\title{
Characterizing Two-Phase Flow Relative Permeabilities in Chemical Flooding Using a Pore-Scale Network Model
}

\author{
Qingjie Liu ${ }^{1}$, Pingping Shen ${ }^{1}$, and $\mathrm{Yu}-\mathrm{Shu} \mathrm{Wu}^{2 *}$ \\ ${ }^{1}$ Research Institute of Petroleum Exploration and Development, Beijing, China \\ 2 Earth Sciences Division, Lawrence Berkeley National Laboratory, Berkeley, USA
}

\begin{abstract}
A dynamic pore-scale network model is presented for investigating the effects of interfacial tension and oil-water viscosity on relative permeability during chemical flooding. This model takes into account both viscous and capillary forces in analyzing the impact of chemical properties on flow behavior or displacement configuration, as opposed to the conventional or invasion percolation algorithm which incorporates capillary pressure only. The study results indicate that both water and oil relativepermeability curves are dependent strongly on interfacial tension as well as an oil-water viscosity ratio. In particular, water and oil relative-permeability curves are both found to shift upward as interfacial tension is reduced, and they both tend to become linear versus saturation once interfacial tension is at low values. In addition, the oil-water viscosity ratio appears to have only a small effect under conditions of high interfacial tension. When the interfacial tension is low, however, water relative permeability decreases more rapidly (with the increase in the aqueous-phase viscosity) than oil relative permeability. The breakthrough saturation of the aqueous phase during chemical flooding tends to decrease with the reduction of interfacial tension and may also be affected by the oilwater viscosity ratio.
\end{abstract}

Key Words: relative permeability, chemical flooding, pore-scale network model, enhanced oil recovery.

\footnotetext{
* Corresponding author. Tel.: +1-510-486-7291; fax: +1-510-486-5686. E-mail: yswu@lbl.gov
} 


\section{Introduction}

In the past few decades, as world oil reserves have dwindled and demands for oil and other sources of energy have increased rapidly worldwide, more efficient development of oil and gas from existing reservoirs has received greater attention. As a result of industrywide efforts to improve oil recovery rates, many tertiary or enhanced oil recovery (EOR) techniques have been developed and applied to various oil fields since the 1970s. In general, EOR methods such as chemical flooding, miscible flooding, and thermal recovery techniques rely on altering the mobility and/or the interfacial tension (IFT) between the displacing and the displaced fluids to improve sweep or displacement efficiency. Among the various EOR approaches developed, chemical flooding, including polymer flooding, surfactant flooding, and alkaline/surfactant/polymer composite flooding, is currently perhaps the most widely used technique in the petroleum industry. This is because this technology has been found to be suitable and cost-effective for improving oil recovery rates from different types of reservoirs, which are subject to a long history of water-flooding operations.

Because of the additional interactions between fluids phases, chemical components, and solid rock, flow behavior in chemical flooding is in general more difficult to characterize than that of water and oil displacement in conventional water flooding. Flow and displacement with chemical flooding depend upon many more factors, such as interfacial tension, viscosity ratio, and flow rate, along with the rock properties of poresize distribution and wettability. Even with the significant progress made in understanding two-phase flow mechanisms during chemical flooding in the past few decades, it remains a challenge to quantitatively assess such flow behavior. It is even more difficult to predict whether this technique can be successfully applied to a given oil field for a feasibility assessment. One of the primary difficulties is the lack of physical insight or constitutive correlations for describing mutual effects or interplay between phases during chemical flooding processes, a deficiency that hinders quantitative analysis.

Past investigations have shown that quantitative characterization of multiphase flow phenomena by chemical flooding is crucial for understanding chemical flooding processes and assessing their applications. Among the various evaluation techniques 
applied, numerical modeling has been among the most important and convenient tools to use in analyzing physical processes, especially, on the temporal and spatial scales relevant to a particular chemical flooding operation in reservoirs.

Since the late 1950s, significant progress has been made in developing and applying numerical simulation techniques in petroleum engineering (e.g., Aziz and Settari, 1979; Coats, 1987; Peaceman, 1997) and groundwater modeling (Huyakorn and Pinder, 1983; Istok, 1989). Continual research effort, driven by the need to develop underground natural resources and resolve subsurface contamination problems, has provided many numerical modeling approaches and models for field applications. Numerical modeling approaches currently used for simulating multiphase flow and transport processes in porous media are generally based on methodologies developed for petroleum and geothermal reservoir simulations, as well as an groundwater modeling. Numerical reservoir simulators have become very sophisticated and are capable of routinely solving problems ranging from simple groundwater flow to coupled multiple-physical-process reservoir simulations. However, practical applications of reservoir simulation techniques (e.g., for analyzing chemical flooding) are often limited by the lack of site-specific fluid and rock parameters. Simulation techniques are also limited in applications because of insufficient studies describing interrelations or mutual influences of multiphase flow and transport processes, such as relative permeability and capillary pressure functions in chemical flooding.

This paper presents a dynamic pore-scale network model and applies it to investigating the effect of interfacial tension and oil-water viscosity on relative permeability during chemical flooding. The main objectives of this work are to (1) obtain some insight into the general behavior of relative permeability functions during chemical flooding operations in oil reservoirs and (2) provide relative permeability curves for use as first-order approximations in reservoir simulation of chemical flooding, when no sitespecific laboratory experimental data are available.

The concept of relative permeability was introduced to describe simultaneous flow of multiphase fluids in a porous medium by an apparent modification or extension of Darcy's law from single-phase to multiple-phase flow conditions (e.g., Scheidegger, 1974; Honarpour et al., 1986). The extended Darcy's law has been the fundamental principle in 
modeling flow and transport processes through porous media. Therefore, relative permeability is among the most important parameters needed for quantitatively investigating multiphase flow dynamics as well as chemical flooding performance. Many field and laboratory studies have shown that the presence of polymer and/or surfactant in injected water or in the aqueous phase has a significant and lasting effect on flow behavior. This effect can generally be described by mathematical models in terms of the relative permeability for evaluating the potential benefits of an EOR project and for simulating the physical processes that may occur over different pore levels of reservoirs during chemical flooding.

In evaluating the performance of chemical flooding in EOR processes, the effect of surfactants on displacement efficiency in EOR systems is of great interest to those concerned with designing cost-effective projects for recovering remaining oil after waterflooding operations. The impact of interfacial tension on relative permeability curves has long been noticed in the petroleum literature. An early study (Leverett, 1939) reported a small but definite tendency for a water-oil system in unconsolidated rocks to exhibit 20 to $30 \%$ higher relative permeabilities if the interfacial tension were decreased from 24 to 5 $\mathrm{mN} / \mathrm{m}$. A later study (Mugan, 1966) showed that a decrease in relative-permeability ratios, with a decrease in interfacial tension, could be deduced from the displacement data by varying interfacial tension values from 5 to $40 \mathrm{mN} / \mathrm{m}$.

More significant effect on relative permeability can be expected to occur at low values of interfacial tension. Talash (1976) presented more experimental results with oil and water relative-permeability curves under various low values of interfacial tension. His results indicated that relative permeabilities for the two phases increased with the decrease in interfacial tension at a given water saturation. Even though the residual oil saturations decreased, the irreducible water saturation did not seem to be affected. The lack of equilibration between the systems in the unsteady-state displacement experiments was manifested in the continual release of oil globules with large volumes of throughput.

In a related work, Gilliand and Conley (1976) provided some invaluable relative permeability data for a low-tension system. They hypothesized that in a low-interfacialtension flooding operation, the oil relative-permeability curves shifted upward or increased under high water saturation, and that the ultimate residual oil saturation could 
be reduced to zero, while the relative permeability to the wetting, aqueous phase was not affected. Batycky and McCaffery (1978) examined steady-state relative permeability data for three interfacial tension levels $(50,0.2,0.02 \mathrm{mN} / \mathrm{m})$; and their data show a reduction in the irreducible brine saturation with the decrease in interfacial tension. In another study, Bardon and Longeron (1980) evaluated the effect of low interfacial tension on gas-oil permeability curves. Their results indicate that the residual oil saturation and relative permeability are both affected strongly by low interfacial tension.

In an effort to quantify the effect of different parameters on multiphase flow behavior, Taber (1969) defined a capillary number in terms of the pressure drop between two points, the flow path length and the interfacial tension. He concluded that as this number increases to a specified value, the residual oil saturation was reduced significantly. A more acceptable capillary number $\left(\mathrm{N}_{\mathrm{c}}\right)$ is defined as a dimensionless group representing the ratio of viscous to interfacial forces affecting the flow of fluid in porous media, as applied to water displacement of oil (Tiab and Donaldson, 1999):

$$
\mathrm{N}_{\mathrm{C}}=\frac{\mu_{\mathrm{w}} \mathrm{v}_{\mathrm{w}}}{\sigma \phi}
$$

where $\mu_{\mathrm{w}}$ is the viscosity of water or aqueous phase, $v_{\mathrm{w}}$ is the flow rate, $\sigma$ is the interfacial tension, and $\phi$ is the effective porosity of formation. The capillary number for typical field water-flooding operations ranges from $10^{-6}$ to $10^{-4}$. Melrose and Brandner (1974) defined the microscopic displacement efficiency $\left(E_{D}\right)$ as the ratio of the mobile oil saturation to the total oil saturation:

$$
E_{D}=\frac{\left(1-S_{o r}-S_{i w}\right)}{\left(1-S_{i w}\right)}=1-\frac{S_{o r}}{1-S_{i w}}
$$

where $S_{\text {or }}$ is the residual oil saturation and $S_{i w}$ is the irreducible water saturation. They explained that as the capillary number increases to greater than a value of $10^{-4}$, the microscopic displacement efficiency will be significantly increased. The effect of the capillary number on the recovery of residual oil is further investigated in Chatzis and 
Morrow (1984) and Morrow and Chatzis (1985). These studies show a decrease in residual saturations for both oil and water phases.

Note that in describing multiphase flow, relative permeability is traditionally estimated as a function of fluid saturation and saturation histories only (Honarpour et al., 1986). This treatment or approximation, however, does not provide sufficient or accurate description of multiphase flow behavior as observed during chemical flooding. Therefore, many research efforts have been devoted to determining the relative permeabilities at specified circumstances of chemical flooding. Amaefule and Handy (1982) and Fulcher et al. (1985) developed a relative permeability model, based on their experimental data, by regression analysis. In this model, relative permeabilities are treated as a function of saturation, interfacial tension, fluid viscosity, and the residual saturation. The residual oil saturation was represented as a function of the capillary number, while the irreducible water saturation was treated as a function of interfacial tension.

In recent years, great attention in the petroleum industry has also been paid to chemical flooding processes using alkalis, polymers and/or surfactants (Krumrine, 1982). This recent interest has been developed because the oil recovery rate has shown to be greatly improved by synergistic or combined action resulting from two, three, or more chemicals. In addition, the amount of expensive surfactants used can be significantly reduced by a factor of 10 when using more economical alkali agents instead. A surfactant within the injected aqueous phase increases the capillary number by reducing the interfacial tension, while a polymer solution improves displacement efficiency by varying the oil and water mobility ratio by enhancing the displacing water-phase viscosity. Furthermore, the alkali is also used to prevent adsorption of chemical components onto the rock and to stimulate the production of natural surfactants from the in situ crude oil.

Compared to the number of experimental or numerical investigations of relative permeability in surfactant flooding, there are few studies available in the literature regarding relative permeability in polymer flooding and polymer-surfactant compositional flooding. A limited number of experimental studies have investigated effects of a polymer injection into two-phase flow system. All these studies indicate that the polymer acts selectively, significantly reducing the relative permeability to water but 
not to oil phase, a phenomenon often referred to as the disproportionate permeability reduction (DPR).

Schneider and Owens (1982) measured polymer-oil relative permeability data by a steady-state procedure on a suite of 18 outcrop and formation core samples. Their studies indicated that the presence of polymers in the water phase had a significant and lasting effect on lowering water relative permeability over the entire water saturation range. Zitha and Vermolen (1999), and Barreau et al. (1997) demonstrated the effect of polymer adsorption on relative permeability. Other studies (e.g., Liang et al., 1995) have attempted to interpret the disproportionate-permeability-reduction phenomenon by different mechanisms, such as polymer retention, partitioning of fluids leading to segregation of oil and water within the porous media, lubrication effect of the polymer (reducing pore wall roughness of the solid matrix), and enhancement of water wettability due to adsorption of hydrophilic molecules.

In a more theoretical view, pore-scale network models have been developed to explain a wide range of phenomena, from capillary pressure characteristics to two- and three-phase relative permeabilities (e.g., Blunt, 1991). In these network models, void or pore space within a formation is described as a lattice of pores connected by throats. The pores and throats are assigned to have some ideal or regular geometry, and rules are developed to determine the multiphase fluid configuration and transport in these idealized elements.

Pore-scale network models can be classified into two categories: quasi-static and dynamic. In the quasi-static model, flow is assumed to occur at an infinitesimal rate, the viscous pressure drop across the network is negligible, and capillary forces completely control the fluid configurations. In most chemical flooding operations, the approximation of quasi-static displacement is generally invalid. For example, large pressure gradients are needed for viscous-polymer-solution flow to occur. In addition, with surfactant flooding, the low interfacial tension weakens the capillary forces, which makes it unlikely for capillarity to be dominant.

Dynamic models relax the constraint that the capillary number be small. In this concept model, the influence of viscous forces is modeled through an explicit computation of the pressure field in the network. Koplick and Lasseter (1985) present a 
dynamic network model for two-phase flow, which allowed for the advance of several menisci during one time step by assuming the same viscosities for the two phases. Lenormand et al. (1988) simulated the dynamics of drainage on a two-dimensional (100 $\times 100)$ network and showed the existence of three basic domains: (1) capillary fingering, (2) viscous fingering, and (3) stable displacement, within which the fluid flow patterns remain unchanged. They noted that because of capillary pressure, the system of equations used to solve the pressure at each node became nonlinear, whereas previously reported work (Koplick and Lasseter, 1985) replaced the nonlinear problem with a sequence of linear problems.

Dias and Payatakes (1986) used a pore-and-throat model with a throat geometry that varied sinusoidally between the adjacent pores. This model simulated the effects of stranding, breakup, coalescence, and shape of ganglion for both favorable and unfavorable viscosity ratios. The issue of steady-state ganglia dynamics was further addressed in the work of Constantinides and Payatakes (1996), who calculated relative permeability as a function of capillary number, viscosity ratio, and coalescence factor.

A new dynamic model of two-phase drainage was developed by Blunt and King (1991) and Hughes and Blunt (2000), with the purpose of studying the effect of viscous and capillary forces on relative permeabilities in 2-D and 3-D networks. Their model simulation results showed that drainage relative permeability may be a function of both viscosity ratio and capillary number. Chaouche et al. (1994) and Haghighi et al. (1994) presented another dynamic network model, similar to the one of Blunt and King (1991), to study drainage processes in heterogeneous porous media.

Vizika et al. (1994) investigated the role of viscosity ratio during forced imbibition and found that the viscosity ratio affects residual oil saturation significantly, even under low-capillary-number conditions. Pereira and Pinczewski (1996) presented a pore network model for drainage dominated three-phase flow. Their simulations agreed with the micromodel work by Øren and Pinczewski (1995). A recent study (Mogensen and Stenby, 1998) provided a more general dynamic model for imbibition, accounting for the flow of a wetting fluid in the corners of pores as well as allowing for ganglion to be mobilized. 
The present work presents a continued effort to use a dynamic pore-scale network model for investigating the effect of interfacial tension and oil-water viscosity on relative permeability during chemical flooding. The model takes into account both viscous and capillary forces in analyzing the impact of chemical properties on flow behavior or displacement configuration. By dynamic pore-scale network modeling, the relative permeability alterations caused by typical chemical factors are investigated. It should be emphasized that this paper does not attempt to directly reproduce experimental situations with actual parameters or to replace physical experiments. Instead, this work intends to investigate the phenomenology of the physical problem for a test configuration, which may reveal some insights into understanding two-phase flow behavior under chemical flooding (as well as encourage future research efforts). As demonstrated in this work, the dynamic pore-scale network model is a useful, promising tool for capturing the key flow mechanism factors as well as for providing insight into relative permeability during chemical flooding operations.

\section{Dynamic Pore-Scale Network Model}

A two-dimensional network model, shown in Figure 1, consists of a set of spherical pores in a triangular lattice, connected by cylindrical throats. The flow occurred in corners or crevices were neglected because the pore throats were modeled with cylindrical rather than a rough or angular cross-section. Sinces our purpose is to investigate the qualitative trends of relative permeability for chemical flooding rather than presents a predictive pore scale network model, neglecting corner flow may be acceptable (Blunt, 2001).

The coordination number in the pore-scale network is six (Figure 1). The frequency distribution of pore size is the key representation for pore structure. From this distribution, statistical parameters such as mean, variance, skewness, and kurtosis can be derived. The pore-throat and pore-body radii are described using a probability frequency distribution given by a special case of the Weibull distribution: 


$$
f(r)=\frac{r-r_{\text {min }}}{\left(r_{\text {max }}-r_{\text {min }}\right)^{2}} \exp \left(-\frac{\left(r-r_{\text {min }}\right)^{2}}{\left(r_{\text {max }}-r_{\text {min }}\right)^{2}}\right)
$$

where $r$ represents the pore-throat radius, and $r_{\min }$ and $r_{\max }$ define the minimum and maximum sizes, respectively. We select the bell-like Weibull distribution for pore radius distribution, because it is based on a function that matches experimental results obtained using a rate-controlled mercury-injection method, in which the frequency of pore-body radius and pore-throat radius can be obtained separately. The distribution used in this study for the pore radius is shown in Figure 2. In this model, we assume that the porehroat radii are uncorrelated, and throat lengths are all set to a specified input value. So, the pore and throat volumes can be calculated as

$$
\mathrm{V}_{\mathrm{b}}=\frac{4}{3} \pi \mathrm{r}_{\mathrm{b}}{ }^{3} \quad \mathrm{~V}_{\mathrm{t}}=\pi \mathrm{r}_{\mathrm{t}}{ }^{2} \mathrm{~L}_{\mathrm{t}}
$$

where $V_{b}$ and $V_{t}$ represent the volume for pore body and throat respectively, $r_{b}$ and $r_{t}$ define the radius of pore body and pore throat, respectively, and $\mathrm{L}_{\mathrm{t}}$ is the length of pore throat. The wettability of the pore surface is assumed to be uniform as water-wet by setting the contact angle at less than $90^{\circ}$, i.e., the heterogeneity of wettability is not considered in this paper, so that the contact angle for all throats are set identically.

We calculate the wetting-phase pressure by applying volume conservation in each pore:

$$
\sum_{j=1, \mathrm{~m}} \mathrm{q}_{\mathrm{ij}}=0
$$

where $\mathrm{q}_{\mathrm{ij}}$ is the volumetric flow rate flowing from pore $\mathrm{i}$ to adjacent pore $\mathrm{j}$ and is obtained from a Darcy-type law in each pore-throat element as: 
$\mathrm{q}_{\mathrm{ij}}=\frac{\pi \mathrm{r}_{\mathrm{ij}}{ }^{4}}{8 \mathrm{~A} \mu_{\mathrm{ij}}}\left(\mathrm{p}_{\mathrm{i}}-\mathrm{p}_{\mathrm{j}}-\mathrm{P}_{\mathrm{c}}\right)^{+}$

where $P_{c}=\frac{2 \sigma \cos \theta}{r}$ is the capillary pressure across the pore throat between nodes $i$ and $j$. In Equation (6), $\mu_{\mathrm{ij}}$ is the viscosity of flowing fluid, and the superscript + denotes the positive part only, i.e., $q_{i j}=0$ as long as $\left(p_{i}-p_{j}<P_{c}\right)$. Otherwise the expression of $q_{i j}$ belongs to a biphasic Poiseuille flow in a tube with a pressure jump at the interface.

By assuming inlet and outlet pressures and calculating the corresponding flow rate using a linear algebra solver, Equation (5) can be solved. Then, we update pore pressure for the next pore-invasion event.

The relative permeability for the displacing and displaced phases was determined by

$$
\mathrm{K}_{\mathrm{rm}}=\frac{\mu_{\mathrm{m}} \mathrm{Q}_{\mathrm{m}} \mathrm{L}}{\mathrm{A}\left(\mathrm{P}_{\text {inlet }}-\mathrm{P}_{\text {outlet }}\right)}
$$

where subscript $\mathrm{m}$ represents displacing or displaced phase, $\mu_{\mathrm{m}}$ is the viscosity of fluid, $\mathrm{Q}_{\mathrm{m}}$ is the flow rate of phase $\mathrm{m}$ across the network, $\mathrm{A}$ is the cross-sectional area of the network model, $\mathrm{L}$ is the length of the network, and $\mathrm{P}_{\text {inlet }}$ and $\mathrm{P}_{\text {outlet }}$ are the inlet and outlet pressures, respectively.

\section{Results and Analyses}

\subsection{Relative Permeability in Surfactant Flooding}

In this work, we seek to reveal the functional relationship between relative permeability and interfacial tension by numerical experiment. Using the dynamic pore-scale network model, discussed above, the competition between the viscous forces and the capillary forces can be evaluated quantitatively. Six virtual surfactant flooding scenarios are 
investigated using the network model, with the values of interfacial tension for the six cases varying from $2.0 \times 10^{-1} \mathrm{mN} / \mathrm{m}$ to as low as $5.0 \times 10^{-4} \mathrm{mN} / \mathrm{m}$.

The relative permeability curves simulated for different values of interfacial tension are presented in Figure 3. In general, Figure 3 shows that the interfacial tension has a significant effect on the relative permeabilities to both phases. At low values (below $10^{-2}$ $\mathrm{mN} / \mathrm{m}$ ), interfacial tension appears to have more impact on water-phase relative permeability than on the oil-phase relative permeability. The modeling results, as shown in Figure 3, also indicate that at high interfacial tension (e.g., higher than $10^{-2} \mathrm{mN} / \mathrm{m}$ ), the effect of interfacial tension on relative permeabilities becomes relatively small. In general, Figure 3 shows that the lower the interfacial tension, the higher the relative permeabilities of oil and water phases. When the interfacial tension is low $\left(\sim 10^{-4} \mathrm{mN} / \mathrm{m}\right)$, the relative permeability curves tend to become more linear compared to the water-phase saturation.

To validate the model, we need to compare simulation results against experimental results. For this purpose, model-predicted relative permeability curves are compared with steady-state experimental data by Fulcher et al. (1985). Figure 4 present several relative permeability curves from the laboratory experiments (Fulcher et al., 1985) used to examine the simulated relative permeabilities generated using the pore-scale network model. The experimental results of Figure 4 were obtained from steady-state relative permeability tests using Berea sandstone cores, with interfacial tension ranging from 5.5 $\mathrm{mN} / \mathrm{m}$ down to $0.0389 \mathrm{mN} / \mathrm{m}$. A comparison of the relative permeability curves in Figures 3 and 4 indicates that a qualitative similarity exists between the simulated curves (Figure 3) and the measurement curves (Figure 4). In particular, it is very encouraging to note that both relative permeability curves show the same trends, i.e., the lower interfacial tension corresponds to the larger relative permeabilities at the same water saturation. This implies that the pore-scale network simulation results are able to capture the important factors that control multiphase flow behavior under surfactant flooding. 


\subsection{Relative Permeability in Polymer-Surfactant Flooding}

In this section, a series of dynamic pore-scale network simulations are carried out with a different oil-water viscosity ratio, $\mathrm{M}$, defined as

$$
\mathrm{M}=\frac{\mu_{\mathrm{o}}}{\mu_{\mathrm{w}}}
$$

where $\mu_{\mathrm{o}}$ is the viscosity of oil. In reservoir engineering, the mobility of a fluid is an important parameter, defined as the effective permeability of the fluid divided by its viscosity. In the pore-scale network, the viscosity ratio is identical to the mobility ratio as long as the effective permeability for the displacing and displaced phase is equal. For simplicity, three viscosity ratios are considered with $M=3 / 5,1 / 1$ and $5 / 3$. The interfacial tension values used range from $1.0 \times 10^{-1} \mathrm{mN} / \mathrm{m}$ ) down to $1.0 \times 10^{-4} \mathrm{mN} / \mathrm{m}$.

Figure 5 shows several simulated relative permeabilities with the combined effect of both viscosity ratio and interfacial tension. The values of interfacial tension vary from $1.0 \times 10^{-1}, 1.0 \times 10^{-2}, 1.0 \times 10^{-3}$ to $1.0 \times 10^{-4} \mathrm{mN} / \mathrm{m}$, with the results shown from Figure 5 a to Figure 5d. The simulation results indicate that at higher interfacial tension values (Figures $5 \mathrm{a}$ and $5 \mathrm{~b}$ ), the relative permeability curves almost overlap each other. This implies that flow under high-interfacial-tension conditions is dominated by capillary forces. Under such conditions, the effect of viscosity ratio on relative permeability is small or may be negligible. With the decrease in interfacial tension, the impact of the viscosity ratio becomes more significant, as shown in Figures $5 \mathrm{c}$ and $5 \mathrm{~d}$. At a low viscosity ratio (i.e., a more viscous water phase), the relative permeability for the water phase is significantly lower than the case with a high viscosity ratio (Figure 5d). As the viscosity of the water phase increases, the relative permeability values for the oil phase also decreases, but the reduction rate is relatively small compared to that in water relative permeability. In the high water saturation range (e.g., $\left.S_{\mathrm{w}}>70 \%\right)$, the reduction in oil relative permeability becomes insignificant, thus indicating that at a high water cut stage, the impact of viscosity ratio upon flow and displacement processes can be neglected. 
In the pore-scale network modeling, we take account only of IFT reduction and water viscosity enhancement, exclusively. It can be seen that the viscosity enhancement may not be the principal reason for DPR, especially under high IFT conditions. From the studies of previous work, other mechanisms such as polymer adsorption and retention, partitioning of fluids (leading to segregation of oil and water within the porous media), the lubrication effect of the polymer (reducing pore wall roughness of the solid matrix), the enhancement of water wettability due to adsorption of hydrophilic molecules-all may contribute the DPR phenomenon.

\subsection{Breakthrough Saturation}

Irreducible water saturation and residual oil saturation are two important parameters in characterizing relative permeability curves as well as displacement efficiency (see Equation (2)). In addition, the correlations between residual oil saturation and capillary number, if determined for a given oil field, will provide the most important guidance for quantitative evaluation of EOR projects by chemical flooding. This breakthrough saturation influences the economic recovery rates from oil fields. For economic purposes, it is important to know when the injected fluid will break through and how much oil can be recovered upon breakthrough. Many of these useful correlations (e.g., relationships between breakthrough saturation, interfacial tension, and viscosity ratio), though difficult and expensive to determine experimentally, can be easily obtained using the dynamic pore-scale network model.

In this paper, the breakthrough saturation is defined as the volume fraction of the water-invaded pores and throats upon water breakthrough. When the breakthrough saturation is low, there is a tendency for the displacing phase to channel, or finger, and to bypass oil, even in homogeneous pore networks. This section demonstrates that such a correlation can be estimated using network-modeling results.

The following pore-scale network modeling consists of more than 40 simulations, with four oil-water viscosity ratios $(\mathrm{M}=3,1,0.6$, and 0.3$)$ incorporated. For each viscosity ratio, ten interfacial tension values are examined, varying from $1.0 \times 10^{1}$ down to $1.0 \times 10^{-4} \mathrm{mN} / \mathrm{m}$. Figure 6 presents the water breakthrough average saturation or 
breakthrough saturation as a function of interfacial tension, corresponding to the different values of viscosity ratio. As shown in Figure 6, with the decrease in the interfacial tension, the breakthrough saturation generally decreases, which is consistent with the previous results with relative permeability. In both high and low ends of interfacial tension ranges, (i.e., interfacial tension $>0.1 \mathrm{mN} / \mathrm{m}$ and interfacial tension $<0.001 \mathrm{mN} / \mathrm{m}$ ), the viscosity ratio has little effect on breakthrough saturation. However, in the intermediate interfacial tension ranges from 0.1 to $0.001(\mathrm{mN} / \mathrm{m})$, the relationship between interfacial tension and breakthrough saturation was no longer monotonous (Figure 6), and the viscosity ratio displays the strong impact on interfacial tension versus breakthrough saturation curves. When the viscosity ratio is large $(M>1)$, with the interfacial tension values from 0.1 to $0.001 \mathrm{mN} / \mathrm{m}$, the breakthrough saturation first sharply decreases with the decrease in the interfacial tension, then reaches its minimum, and eventually increases with the increase in interfacial tension (shown in squared and circled curves in Figure 6). On the other hand, when the viscosity ratio is low or the water-phase viscosity is high, the breakthrough average water saturation curves show a maximum at the intermediate value of interfacial tension amounting to $0.01 \mathrm{mN} / \mathrm{m}$, shown by the triangled curves of Figure 6 .

The low breakthrough saturations imply strong fingering, while the high breakthrough saturations indicate less fingering or a stable displacement developed with better efficiency. Figure 7 depicts three types of microscopic displacement patterns occurring in the pore-scale network simulation results. In Figure 7a, fingering is so strong that the resulting breakthrough saturation is very low. This flow pattern occurs when the interfacial tension is extremely low and corresponds to the capillary fingering (Lenormand et al., 1988). Figure 7c shows the case in which weak fingering leads to high breakthrough saturation or better displacement efficiency. This pattern will be observed when the interfacial tension is relatively high or oil-water viscosity ratio is low. Figure $7 \mathrm{~b}$ presents the intermediate case, in which capillary forces and viscous forces are comparable or of the same order.

In chemical flooding, the sweep or displacement efficiency is improved mostly through mobility control. In polymer flooding, for example, the microscopic efficiency improvement is achieved mainly by the injection of surfactant solution. In the polymersurfactant composite flooding, on the other hand, the coupling of surfactant and polymer 
may offset or counteract each other's effect upon breakthrough. Figure 6 indicates that the significant effect of polymers occurs only at certain ranges of interfacial tension.

\section{Summary and Concluding Remarks}

The dynamic pore-scale network model is used here to study relative permeability as well as two-phase flow behavior in reservoirs under chemical flooding. This study shows that the relative permeability for two-phase flow and displacement under chemical flooding is not only a function of saturation, but is also strongly dependent on interfacial tension as well as the oil-water viscosity ratio. The model results indicate that the relative permeability for both oil and water phases increases with the decrease in interfacial tension, especially for interfacial tension value ranges below $10^{-2} \mathrm{mN} / \mathrm{m}$. In addition, the oil-water viscosity ratio is found to have only a small effect under conditions of high interfacial tension. When the interfacial tension is low, however, water relative permeability decreases more rapidly than the oil relative permeability with the increase of the aqueous-phase viscosity. The breakthrough saturation of the aqueous phase during chemical flooding, as predicted by the model, tends to decrease with reduction of interfacial tension, and can also be affected by oil-water viscosity ratio.

To verify the model results, we compared simulated relative permeabilities to the experimental results from the literature and found good qualitative agreement. This indicates that the dynamic pore-scale network model is able to capture the main factors that control flow and displacement processes for chemical flooding. This work thus demonstrates that the dynamic pore-scale network model is likely to be a very useful tool for the investigation of complex flow and displacement behavior involved in chemical flooding. When no laboratory data, such as relative permeability curves are available for quantitative assessment of chemical flooding operations for a specific field, a dynamic model, if constructed and calibrated properly, may provide a first-order approximation as an alternative approach for some insight into chemical flooding practices.

To improve confidence in predictions from a wider range of chemical flooding factors, it would be preferable to have a library of networks representing different pore structures and chemical flooding factors. An even more promising application of predictive pore- 
scale network models is one in which experimental data is not available or difficult to obtain. Available experimental data can also be used to calibrate the pore-scale network model results to a specific core condition. In different chemical flooding processes, many factors should be considered for feasibility studies. Assessing the impact of these factors and variables on relative permeability may be carried out as reliably using network modeling as extrapolation from experimental data alone.

\section{Acknowledgment}

This work was supported by the China National Key Basic Research Development Program under grant 1999022510. The authors would like to thank Dmitriy Silin and Dan Hawkes for their review of this paper. This work was also supported in part by the Lawrence Berkeley National Laboratory through the U.S. Department of Energy under Contract No. DE-AC03-76SF00098.

\section{References}

Amaefule J. O. and Handy L. L.: 1982, The effect of interfacial tension on relative oil/water permeabilities of consolidated porous media, Soc. Pet. Eng. J., 371-381.

Aziz, K. and Settari A.: 1979, Petroleum Reservoir Simulation, Applied Science Publishers LTD, London,.

Bardon C. and Longeron D.: 1980, Influence of very low interfacial tensions on relative permeability, Soc. Pet. Eng. J., 391-401.

Barreau P., Lasseux D. and Bertin H.: 1997, Polymer adsorption effect on relative permeability and capillary pressure: Investigation of a pore scale scenario, SPE 37303, SPE International Symposium on Oilfield Chemistry, Houston, USA.

Batycky J. P. and McCaffery F. G.: 1978, Low interfacial tension displacement studies, paper 78.29.26 presented at the Petroleum Soc. Of CIM, 29 ${ }^{\text {th }}$ Annual Technical Meeting, Calgary, Canada.

Blunt M. J. and King P.: 1991, Relative permeability from two and three dimensional pore scale network modeling, Transport in Porous Media, 6, 407-433. 
Blunt M. J.: 2001, Flow in porous media-pore network models and multiphase flow, Current Opinion in Colloid \& Interface Science, 6, 197-207.

Chaouche M., Rakotamala N., Salin D., Xu B. and Yortsos Y.C.: 1994, Capillary effects in drainage in heterogeneous porous media: Continuum modeling, experiments and pore network simulations, Chem. Eng. Sci., 49, 2447-2466.

Chatzis I., Morrow N. R.: 1984, Correlation of Capillary Number Relationships for sandstone, Soc. Pet. Eng. J., 555-562.

Coats, K. H.: 1987, Reservoir Simulation, Chapter 48, Petroleum Engineering Handbook, Society of Petroleum Engineers, Richardson, Texas, 48-1-48-20.

Constantinides G. N. and Payatakes A. C.: 1996, Network simulations of steady state two phase flow in consolidated porous media, AIChE J., 42, 369-382.

Dias M. M. and Payatakes A. C.: 1986, Network models for two-phase flow in porous media, I. Immiscible micro displacement of nonwetting fluids, J. Fluid Mech., 164, 305-338.

Fulcher R. A., Ertekin T. and Stahl C. D.: 1985, Effect of capillary number and its constituents on two phase relative permeability curves, J. Petrol. Technol., 249-260

Gilliland H. E. and Conley F. R.: 1975, Surfactant waterflooding, Proc. 9th World Petroleum Congress, Tokyo.

Haghighi M., Xu B. and Yortsos Y. C.: 1994, Visualization and simulation of immiscible displacement in fractured systems using micromodels: I, Drainage, J. Coll. Int. Sci., $166,168-179$.

Honarpour, M., Koederitz L. and Harvey A. H.: 1986, Relative permeability of petroleum reservoirs, CRC Press, Inc., Boca Raton, Florida.

Hughes R. G. and Blunt M. J.: 2000, Pore scale modeling of rate effects in imbibition, Transport in Porous Media, 40(3), 295-322.

Huyakorn, P. S. and Pinder G. F.: 1983, Computational Methods in Subsurface Flow, Academic Press, Inc., New York.

Istok, J.: 1989, Groundwater Modeling by the Finite Element Method, American Geophysical Union Water Resources Monograph 13.

Koplik J. and Lasseter T. J.:1985, Two-phase Flow in Random Network Models of Porous Media, Soc. Pet. Eng. J., 89-100. 
Krumrine P.H., Falcone J.S. and Campbell T.C., 1982, Surfactant flooding 1: The effect of alkaline additives on IFT, surfactant adsorption and recovery efficiency, Soc. Pet. Eng. J., 503-513.

Lenormand R., Touboul E. and Zarcone C.:1988, Numerical model and experiments on immiscible displacement in porous media, J. Fluid Mech., 189, 165-187.

Leverett M. C.: 1939, Flow of oil water mixtures through unconsolidated sands, Trans. AIME, 132, 149-171.

Liang J. T., Sun H. and Seright R. S.: 1995, Why do gels reduce water permeability more than oil permeability? SPE Reserv. Engng., 282-286.

Melrose J. C. and Brandner, C. F.: 1974, Role of capillary determining microscopic displacement efficiency for oil recovery by waterflooding, J. Canada. Petrol. Technol., Oct., 54-62.

Mogensen K. and Stenby E. H.: 1998, A dynamic two-phase pore scale model of imbibition, Transport in Porous Media, 32, 299-327.

Morrow N. R., Chatzis I. and Lim H.: 1985, Relative permeabilities at reduced residual saturations, Canad. Petrol. Technol., 62-69.

Mugan N.: 1966, Interfacial effects in immiscible liquid displacement on porous media, Soc. Pet. Eng. J., 247-253.

Oren P. E. and Pinczewski W. V.: 1995, Fluid distribution and pore scale displacement mechanism in drainage dominated three phase flow, Transport in Porous Media, 20(1-2), 103-133.

Peaceman, D. W.: 1977, Fundamentals of Numerical Reservoir Simulation, Developments in Petroleum Sciences, 6, Elsevier Scientific Publishing Company, Amsterdam-Oxford-New York.

Pereira G. G. and Pinczewski W. V.: 1996, Pore scale network model for drainage dominated three phase flow in porous media, Transport in Porous Media, 24(2), 157166.

Scheidegger, A. E.: 1974, The Physics of Flow through Porous Media, Third Edition, University of Toronto Press, Toronto.

Schneider F. N. and Owens W.W.: 1982, Steady state measurements of relative permeability for polymer/oil systems, Soc. Pet. Eng. J., 79-85. 
Talash A. W.: 1976, Experimental and calculated relative permeability data for system containing tension additives, SPE 5810, SPE Improved Oil Recovery Symposium, Tulsa, USA.

Taber J. J.: 1969, Dynamic and Static forces required to remove a discontinuous oil phase from porous media containing both oil and water, Soc. Pet. Eng. J., 3-12.

Tiab D. and Donaldson E. C.: 1999, Petrophysics: Theory and Practice of Measuring Reservoir Rock and Fluid Transport Properties, Gulf Professional Publishing, Houston, 300-301

Vizika O., Avraaam D. G. and Payatakes A. C.: 1994, On the role of the viscosity ratio during low capillary number forces imbibition in porous media, J. Coll. Int. Sci., 165, 386-401.

Zitha P. L. J. and Vermolen F. J.: 1999, Modification of two phase flow properties by adsorbed polymers and gels, SPE 54737, SPE European Formation Damage Conference, Hague, Netherlands. 


\section{List of Figure Captions:}

Figure 1. Schematic of the pore-scale network model $(z=6)$

Figure 2. Probability frequency distribution used for pore radii

Figure 3. Simulated relative permeability curves with different interfacial tension values

Figure 4. Oil-water relative permeability curves from experiments (Fulcher et al., 1985)

Figure 5. Simulated Relative permeability with the combined effect of viscosity and interfacial tension

Figure 6. The correlations between water breakthrough saturation, interfacial tension and viscosity ratio

Figure 7. Microscopic displacement patterns: (a) capillary fingering, (b) viscous fingering, and (c) stable displacement. 


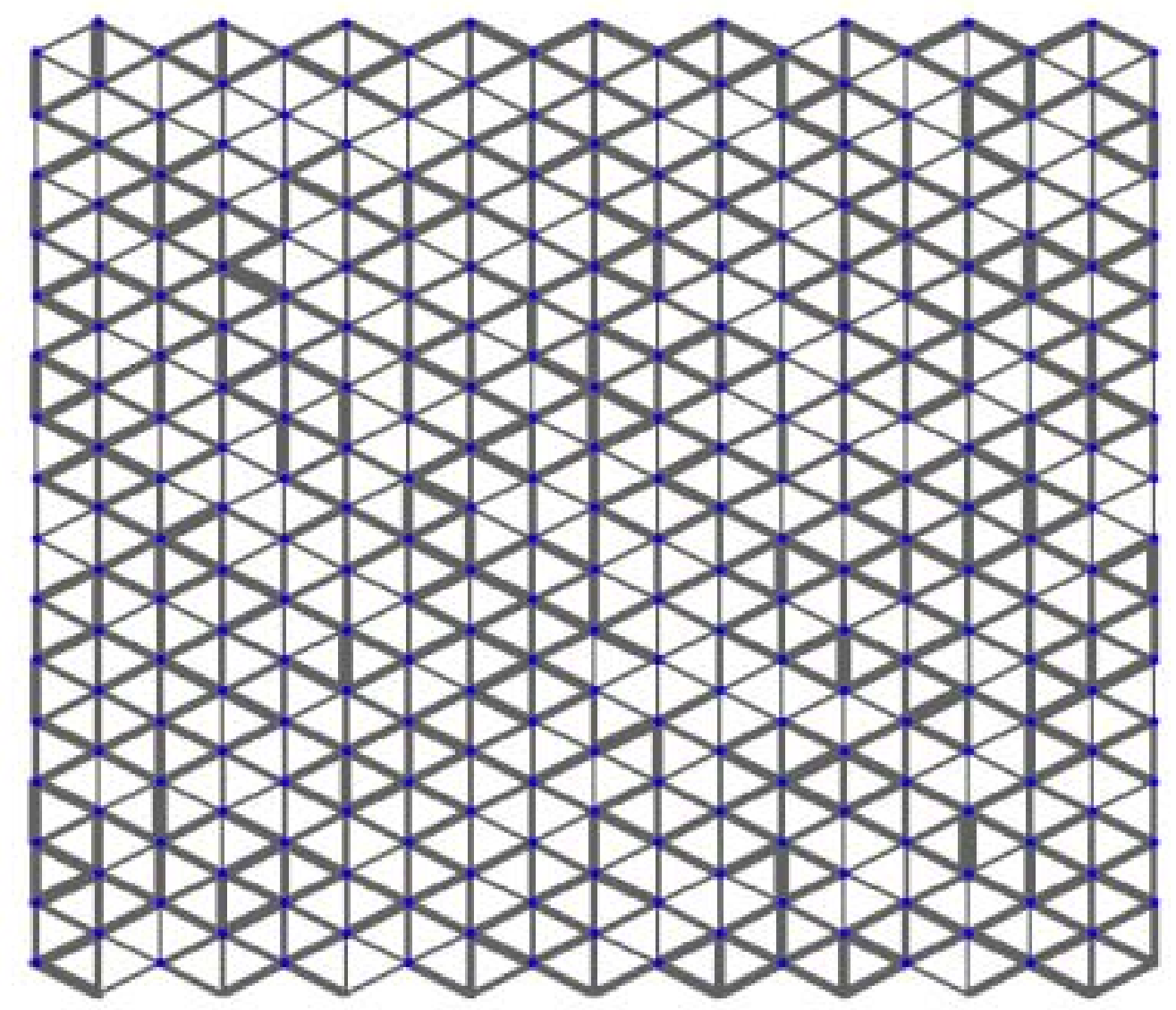

Figure 1. Schematic of the pore-scale network model $(\mathrm{z}=6)$ 


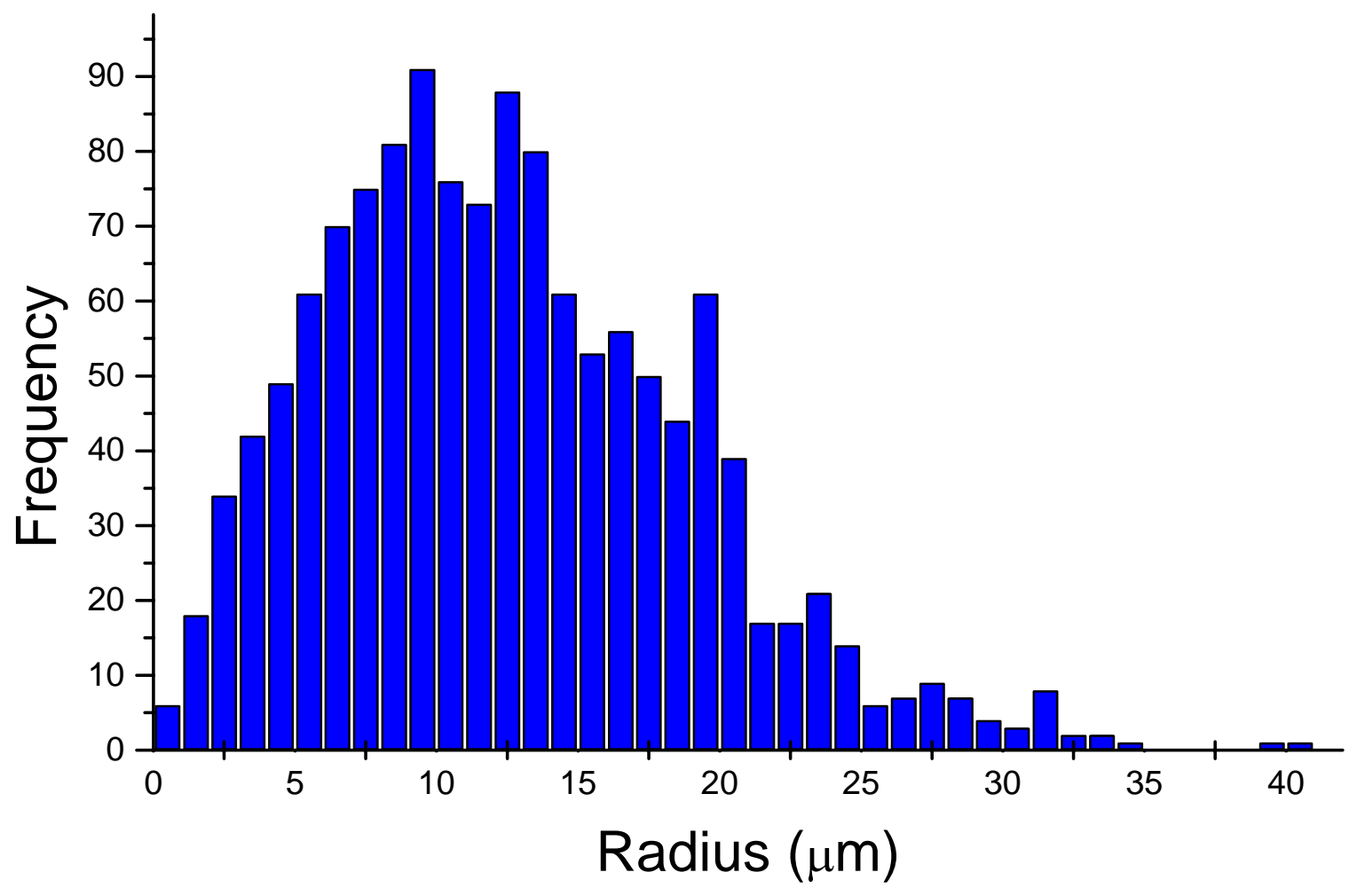

Figure 2. Probability frequency distribution used for pore radii. 


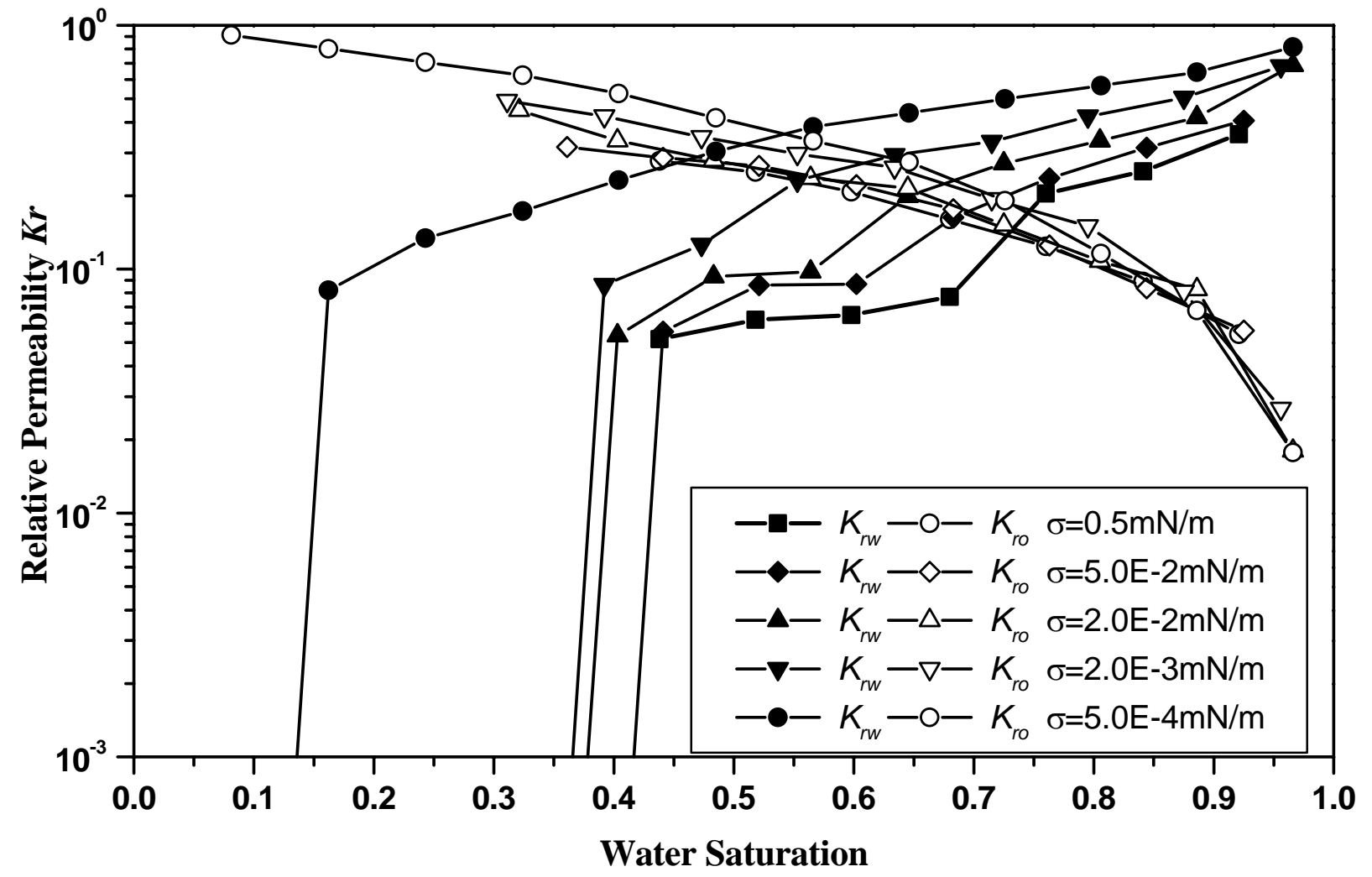

Figure 3. Simulated relative permeability curves with different interfacial tension values 


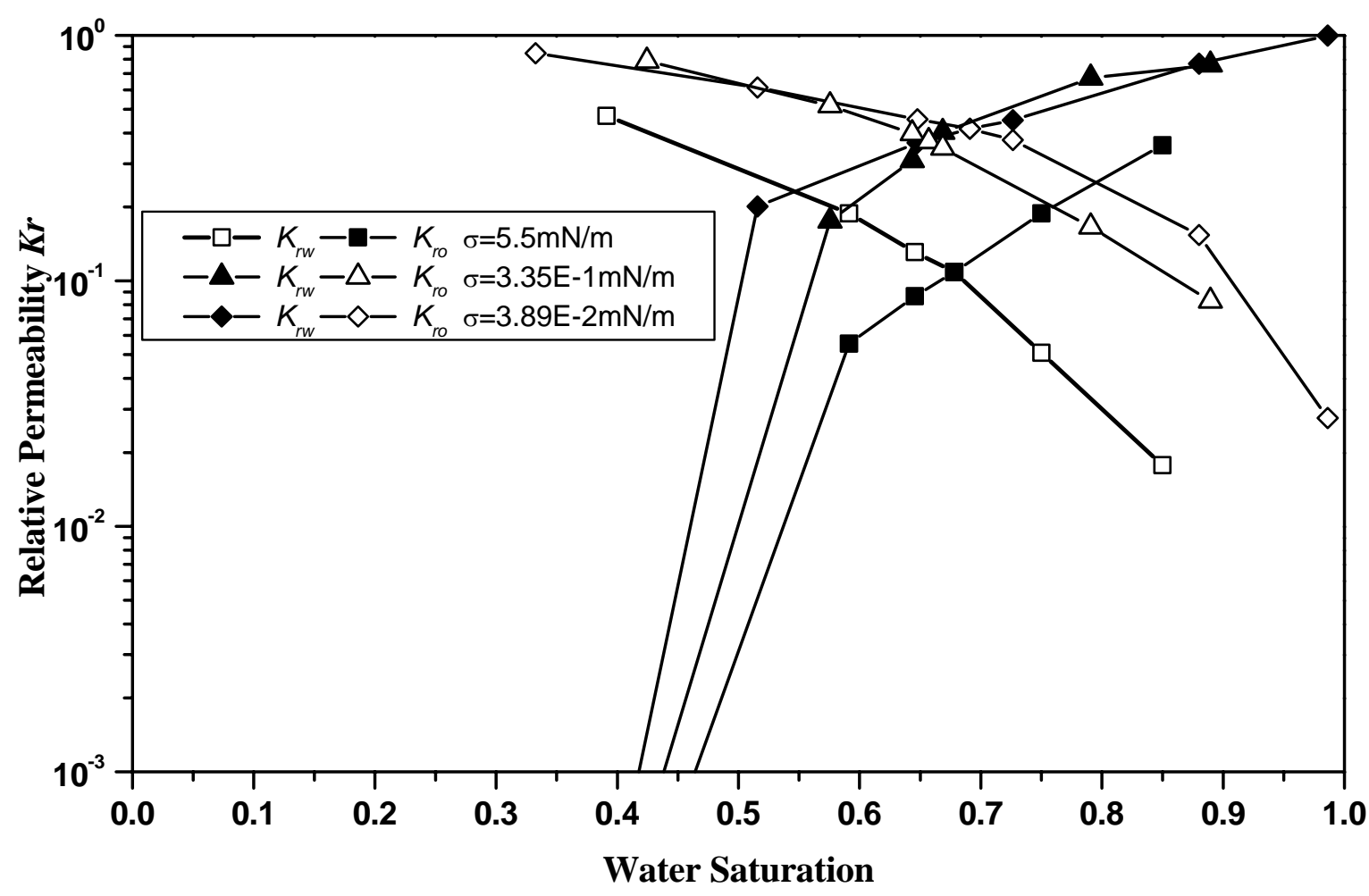

Figure 4. Oil-water relative permeability curves from experiments (Fulcher et al., 1985) 

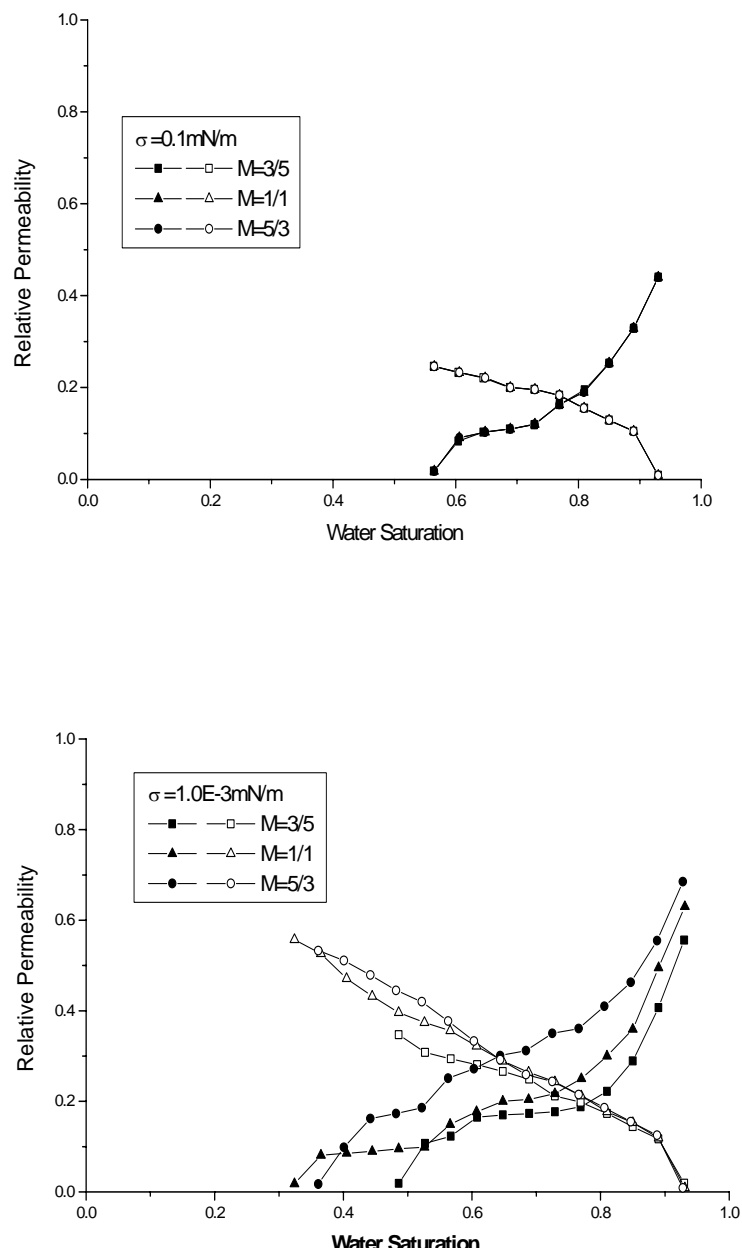

c

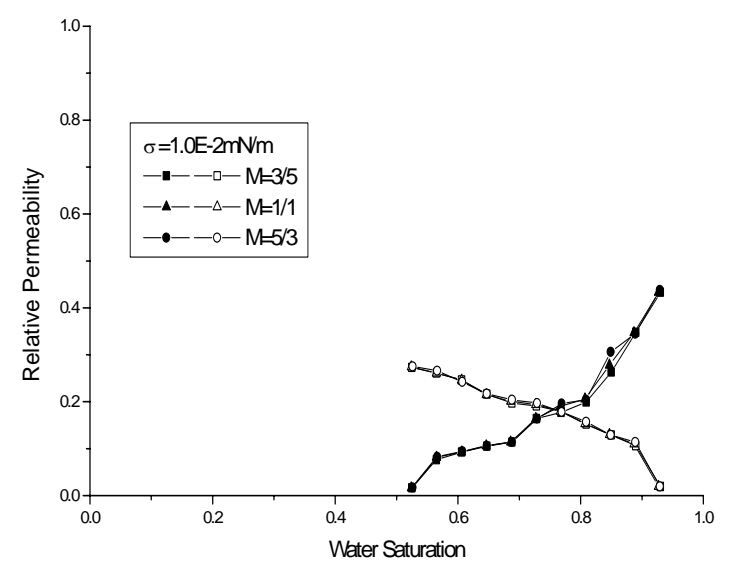

b

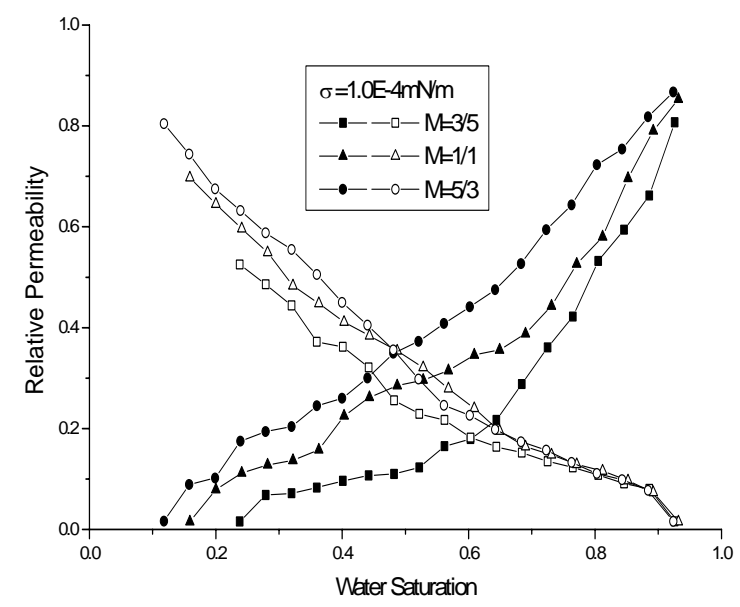

d

Figure 5. Simulated Relative permeability with the combined effect of viscosity and interfacial tension 


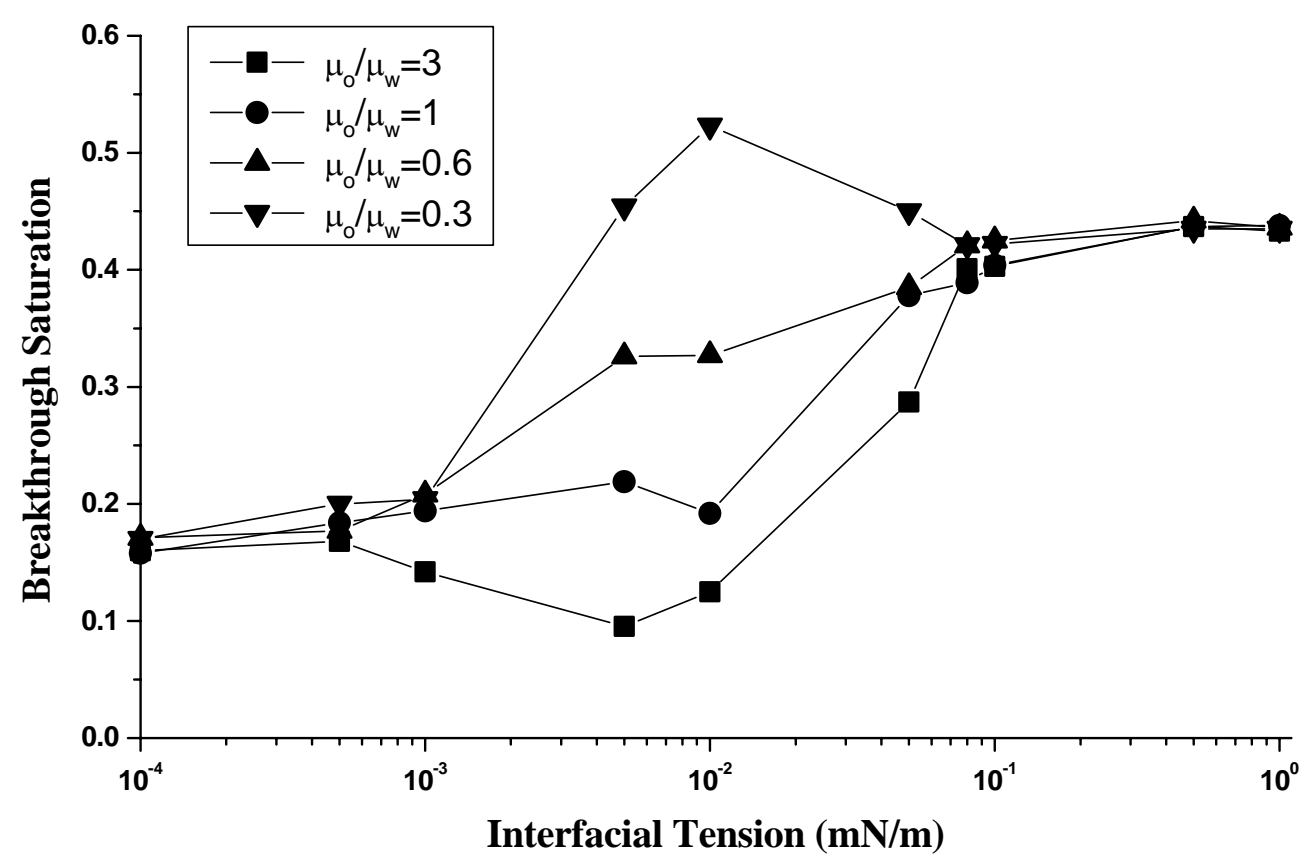

Figure 6. The correlations between water breakthrough saturation, interfacial tension and viscosity ratio 

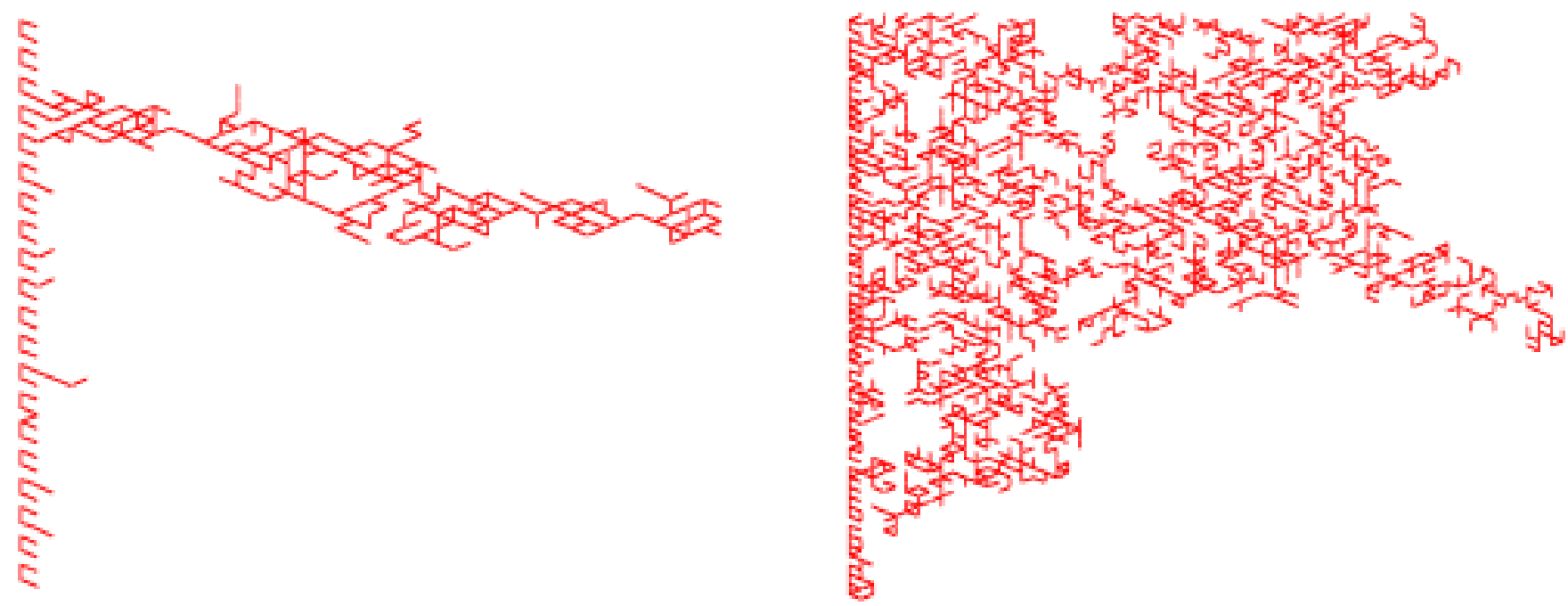

a.

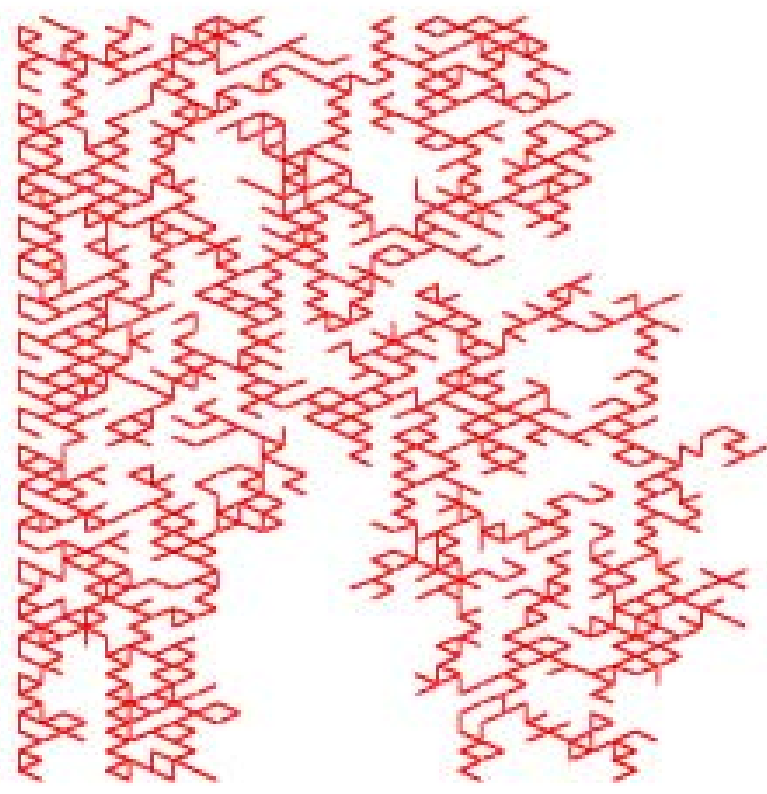

c.

Figure 7. Microscopic displacement patterns: (a) capillary fingering, (b) viscous fingering, and (c) stable displacement 